
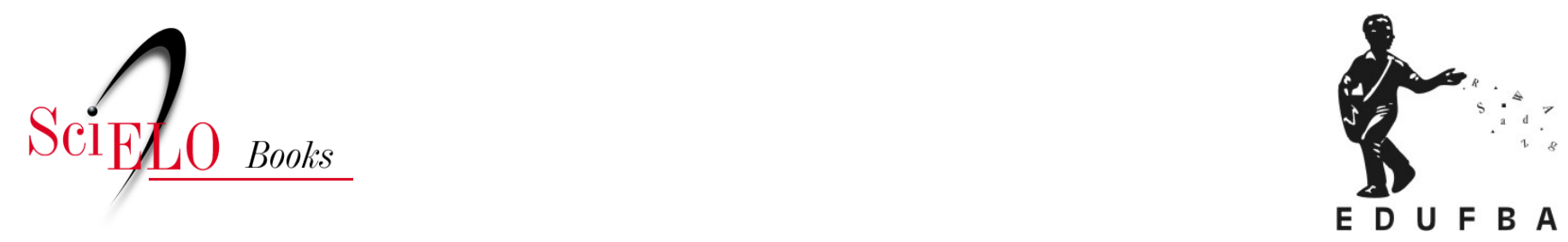

\title{
Técnicas de medidas antropométricas
}

\author{
Lílian Ramos Sampaio \\ Maria da Conceição Monteiro da Silva \\ Tatiane Melo de Oliveira \\ Christiane Ishikawa Ramos
}

SAMPAIO, L.R., SILVA, M.C.M., OLIVEIRA, T.M., and RAMOS, C.I. Técnicas de medidas antropométricas. In: SAMPAIO, L.R., org. Avaliação nutricional [online]. Salvador: EDUFBA, 2012, pp. 89-101. Sala de aula collection. ISBN: 978-85-232-1874-4.

https://doi.org/10.7476/9788523218744.0007.

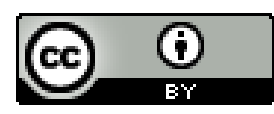

All the contents of this work, except where otherwise noted, is licensed under a Creative Commons Attribution $\underline{4.0 \text { International license. }}$

Todo o conteúdo deste trabalho, exceto quando houver ressalva, é publicado sob a licença Creative Commons Atribição 4.0.

Todo el contenido de esta obra, excepto donde se indique lo contrario, está bajo licencia de la licencia $\underline{\text { Creative }}$ Commons Reconocimento 4.0. 


\title{
Técnicas de medidas antropométricas
}

\author{
Lílian Ramos Sampaio \\ Maria da Conceição Monteiro da Silva \\ Tatiane Melo de Oliveira \\ Christiane Ishikawa Ramos
}

\section{Introdução}

Para que as medidas antropométricas sejam realizadas com maior precisão, é necessário que o medidor domine as técnicas de medidas e conheça os instrumentos utilizados. A maioria das medidas é realizada com o indivíduo em posição anatômica, ou seja, em posição ereta, com a face voltada para frente em direção ao Plano Horizontal de Frankfurt (olhar para o horizonte), com os braços estendidos ao longo do corpo e com as palmas das mãos voltadas para frente. A aferição de medidas em membros superiores ou inferiores deve ser realizada de preferência no lado não dominante. 


\section{Peso}

\section{Peso (Em pé)}

Para aferir o peso, utiliza-se uma balança devidamente calibrada, de plataforma ou eletrônica. O ideal é que esta medida seja aferida antes das principais refeições. $\mathrm{O}$ indivíduo deverá estar descalço e utilizar o mínimo de acessórios e roupas possíveis, de preferência leves, para então ser posicionado em pé no centro da balança, com o peso distribuído igualmente em ambos os pés. $\mathrm{O}$ medidor deverá se posicionar em frente à escala e a medida deverá ser aferida e registrada com exatidão. $\mathrm{O}$ instrumento não deve ser posicionado sobre tapete, carpete ou piso irregular.

\section{Peso (Deitado) - Crianças}

O medidor deve seguir as recomendações quanto à calibração, refeições e posicionamento para a leitura, especificadas para a medição em pé. A criança deverá ser posicionada deitada ou sentada na balança pediátrica com o mínimo de roupa possível, de preferência nua. Caso use fraldas, recomenda-se que seja retirada, a fim de não alterar o peso. A balança deve ser posicionada sobre mesa de superfície plana em piso regular.

\section{Estatura}

A estatura pode ser aferida ou estimada a partir da medida da extensão dos braços ou através da fórmula de estimativa de altura, que utiliza a altura do joelho. Normalmente, os instrumentos utilizados são o estadiômetro e o infantômetro. Há também o 
antropômetro fixo à balança, entretanto este apresenta menor acurácia quando comparado ao estadiômetro.

\section{Estatura (Em pé)}

O indivíduo deverá estar descalço ou usando meias finas e roupas leves, de forma a visualizar a posição do corpo, e sem nenhum adereço na cabeça que possibilite alteração da medida. Deverá permanecer em posição anatômica com panturrilha, glúteos, ombros e cabeça tocando a parede ou superfície vertical do dispositivo de medida, sempre que possível. Com a face voltada para frente, no Plano de Frankfurt, o suporte deverá ser posicionado sobre a cabeça, de tal forma que pressione apenas o cabelo. $\mathrm{O}$ medidor deverá estar em frente à escala e a medida ser aferida cuidadosamente no centímetro mais próximo. Caso a parede seja utilizada como suporte de medida, esta deve ser lisa e não possuir rodapés. $\mathrm{O}$ instrumento não deve ser posicionado sobre tapete, carpete ou piso irregular.

\section{Comprimento (Deitado) - Crianças menores de 24 meses}

A criança deverá estar deitada em mesa com superfície plana posicionada em piso regular com a face voltada para cima, no Plano de Frankfurt, e a cabeça encostada na parte fixa do infantômetro. Com os joelhos retos e as pernas encostadas sobre a superfície da mesa, a parte móvel do infantômetro deverá ser deslocada e pressionada sobre a região plantar. É necessário segurar os joelhos, pressionando-os firmemente sobre a mesa de medida, para mantê-la na posição adequada. Registra-se o comprimento no milímetro mais próximo. 


\section{Estatura recumbente}

A estatura recumbente é uma técnica utilizada em casos onde é inviável a movimentação do indivíduo. O mesmo deve permanecer deitado em posição supina e com leito horizontal completo. O lençol da cama é marcado na altura da extremidade da cabeça e da base dos pés (pés flexionados), do lado direito do indivíduo, sendo medida a distância entre as duas marcas com o auxílio de uma fita métrica flexível.

\section{Estimativa da estatura: pode ser realizada utilizando a medida da extensão dos braços e o comprimento das pernas}

\section{Extensão dos braços/ Envergadura dos braços}

Para a realização desta medida, o individuo deve ser posicionado em pé, de costas para a parede; os braços devem ficar estendidos, formando um ângulo de $90^{\circ}$ com o corpo (na altura do ombro), sendo aferida a distância entre os dedos médios do indivíduo com o auxílio de uma fita métrica flexível. Caso não seja possível a extensão dos dois braços, a medida poderá ser aferida medindo a distância entre o dedo médio de um dos braços estendidos e o meio do externo na altura do ombro. Multiplica-se o resultado por dois.

\section{Comprimento da perna (Knee Height)}

O comprimento da perna é utilizado para a estimativa da altura, principalmente em idosos, a partir da fórmula proposta por Chumlea e outros (1985). 
O indivíduo deverá estar sentado o mais próximo possível da extremidade da cadeira, com a perna flexionada, formando um ângulo de $90^{\circ}$ com o joelho e o tornozelo - caso a altura da cadeira não seja compatível com o comprimento da tíbia, utilizar sob os pés um apoio. A parte fixa do instrumento é posicionada na parte inferior dos pés, no meio do calcanhar, e a outra na superfície anterior do joelho, acima dos côndilos do fêmur e próximo à rótula. A régua do calibrador deve ser mantida paralela à tíbia, para tanto, a haste móvel deverá ser posicionada a 2 ou 3 dedos em direção à coxa. Antes da leitura, uma pressão suave nos suportes do calibrador deve ser exercida.

Caso esteja acamado, o indivíduo deverá estar em posição supina, com a perna flexionada, formando um ângulo de $90^{\circ} \mathrm{com}$ o joelho e o tornozelo. A medida deve ser aferida com os mesmos critérios para a posição supracitada.

\section{Circunferências}

Para aferir as circunferências, utiliza-se a fita inelástica. Ao realizar as medidas, deve-se atentar para a posição linear e horizontal da fita, evitando compressão ou folga dos tecidos. A variação máxima aceita entre duas medidas consecutivas é de $1 \mathrm{~cm}$, para as grandes circunferências (como quadril, cintura e coxa), e 0,5 $\mathrm{cm}$, para as pequenas (como braço, tornozelo e pescoço). É importante ressaltar que a aferição da circunferência braquial deve ser realizada no lado não dominante do indivíduo, seguindo os padrões de referência adotados na América do Norte. Sempre que possível, realizar duas medidas e utilizar a média das duas. No caso de utilização dos dados para pesquisas, recomenda-se 
aferição por dois medidores, observando-se sempre a variação máxima entre as medidas.

\section{Perímetro cefálico}

A criança deve estar na posição anatômica ou sentada e o medidor lateralmente à mesma. Com a cabeça da criança posicionada no Plano de Frankfurt, o medidor deverá circundar a fita acima da cavidade supra-orbital e sobre o occipital na circunferência máxima. Deve-se ter cuidado para que a fita esteja no mesmo nível em ambos os pontos supracitados. É preciso pressionar o suficiente para comprimir apenas o cabelo. A leitura deverá ser realizada no milímetro mais próximo.

\section{Perímetro torácico}

A circunferência do tórax é mais utilizada em crianças menores de 5 anos. Para aferir esta medida, a criança deverá estar em posição anatômica ou sentada, com os braços levemente levantados de tal forma que permita a passagem da fita em volta do tórax na altura dos mamilos. Após a fita ser posicionada, a criança deverá manter os braços relaxados ao longo do corpo. A leitura é realizada ao final da expiração, com o medidor em frente ao indivíduo, desviando-se levemente para o lado.

\section{Circunferência do pescoço}

Esta medida é aferida com o indivíduo sentado e ereto, com a face voltada para frente, no Plano de Frankfurt. A fita deve ser posicionada horizontalmente, acima da proeminência laríngea (pomo de Adão). A leitura é realizada lateralmente. 


\section{Circunferência do braço}

O indivíduo deve estar em posição anatômica, de lado para o medidor. Flexiona-se o braço do indivíduo em direção ao tórax, formando um angulo de $90^{\circ}$ com o cotovelo; localiza-se e marca-se o ponto médio entre o processo acromial e a extremidade do olécrano. Após marcar o ponto médio, o indivíduo deverá estender o braço ao longo do corpo com a palma da mão voltada para a coxa. A fita deverá contornar o braço no ponto marcado de forma ajustada, evitando compressão ou folga da pele. A leitura é realizada no milímetro mais próximo.

Caso esteja deitado, o indivíduo deverá estar olhando para cima com a cabeça apoiada no travesseiro. A localização do ponto médio é realizada da mesma forma utilizada para a posição em pé, porém, para a aferição da medida, os braços devem estar estendidos ao lado do corpo, com a palma da mão voltada para cima e os cotovelos apoiados sob alguma superfície, a fim de afastar o braço da cama, possibilitando a realização da medida.

\section{Circunferência da coxa}

$\mathrm{Na}$ aferição desta medida, o indivíduo deverá estar na posição ortostática, com as pernas levemente afastadas. Deve-se localizar o ponto médio entre a linha inguinal e a borda superior da patela. A partir deste ponto meso-femural, circundar a fita horizontalmente, realizando a leitura lateralmente.

\section{Circunferência da cintura}

O indivíduo deverá estar em posição anatômica. Na linha média axial, localiza-se e marca-se o ponto médio entre a crista ilíaca e o rebordo da última costela, no qual circunda a fita. Deve-se 
observar o posicionamento horizontal da fita ao longo da cintura e o ajuste, de forma a evitar folga ou compressão da pele. O medidor deverá posicionar-se lateralmente ao indivíduo e a leitura deverá ser realizada no momento da expiração.

\section{Circunferência do quadril}

O indivíduo deverá estar usando roupas de tecido fino, de preferência ajustada ao corpo, em posição ortostática, e o medidor deverá estar agachado lateralmente ao indivíduo, para que possa visualizar melhor a parte mais saliente do quadril, por onde deverá circundar a fita. A fita deve ser posicionada de forma horizontal e ajustada ao corpo, evitando-se folga ou compressão da pele. Caso o indivíduo não utilize roupas leves, deve-se comprimir um pouco mais a fita, de forma a minimizar as interferências da roupa na medida.

\section{Circunferência da panturrilha}

O indivíduo deverá estar deitado ou sentado na mesma posição utilizada para a altura do joelho. A medida deve ser aferida lateralmente, posicionando a fita na circunferência máxima da panturrilha, e a leitura deve ser realizada no milímetro mais próximo.

\section{Pregas Cutâneas}

Para aferir as pregas cutâneas, utilizamos adipômetros ou plicômetros, com a leitura realizada em milímetros. Recomenda-se aferir a mesma prega três vezes, soltando-a e pinçando-a novamente entre as medidas. 
Instruções gerais

- $\quad$ Identificar e marcar o local a ser pinçado, do lado não dominante do indivíduo;

- $\quad$ Segurar a prega formada pela pele e tecido adiposo com os dedos polegar e indicador a $1 \mathrm{~cm}$ do ponto marcado;

- Manter a prega entre os dedos enquanto a medida é aferida;

- Pinçar a prega com o calibrador exatamente no local marcado a $1 \mathrm{~cm}$ dos dedos;

- $\quad$ Evitar modificar a posição do calibrador. O mesmo deve ser posicionado perpendicularmente em relação à prega;

- $\quad$ Realizar a leitura de 2 a 3 (GIBSON, 1993; LEE; NIEMAN, 1993) ou 4 (LOHMAN, 1988) segundos após o pinçamento, no milímetro mais próximo;

- Caso o indivíduo esteja acamado, recomenda-se o desprendimento da prega a $1 \mathrm{~cm}$ abaixo do ponto de pinçamento, a fim de facilitar a leitura.

\section{Prega Tricipital}

O indivíduo deverá estar em posição ortostática, de costas para o medidor. Marcar-se dois pontos na região onde localiza-se o tríceps braquial: o ponto médio entre o acrômio e o olécrano (ponto marcado para medir a circunferência do braço), em que se posiciona horizontalmente o aparelho, e um ponto a $1 \mathrm{~cm}$ acima deste, onde será formada a prega para desprendimento do tecido adiposo.

Caso o indivíduo esteja deitado, deve ser posicionado de lado, com as costas voltadas para o medidor, o tronco em linha reta, os 
ombros perpendiculares à espinha e à mesa de exame ou cama, as pernas levemente flexionadas e a cabeça apoiada sobre o braço não utilizado para medida. O ponto médio é marcado, seguindo a mesma orientação para circunferência do braço, com o indivíduo deitado, e a prega deverá ser desprendida do tecido muscular a $1 \mathrm{~cm}$ abaixo do ponto médio, no sentido vertical, a fim de facilitar a leitura da medida no aparelho.

\section{Prega bicipital}

O indivíduo deverá estar em posição anatômica, de frente para o medidor. Para realizar esta medida, deve-se transferir o ponto marcado da prega tricipital para a região bicipital e marcar a $1 \mathrm{~cm}$ acima deste. No primeiro ponto, posiciona-se o aparelho horizontalmente e, no último, desprende-se a prega.

\section{Prega subescapular}

O indivíduo deverá estar em posição ortostática, de costas para o medidor. Deve-se solicitar que o mesmo dobre o braço em direção às costas, formando um ângulo de $90^{\circ}$ com o cotovelo. Com o auxílio dos dedos, localizar e marcar um ponto logo abaixo do ângulo inferior da escápula. Marcar outro ponto a $1 \mathrm{~cm}$ acima deste, na diagonal, de forma que a fita mantenha um ângulo de $45^{\circ} \mathrm{com}$ a coluna. Com os braços relaxados, estendidos ao longo do corpo, a prega é desprendida no ponto superior e o aparelho posicionado diagonalmente, em direção à prega, no ponto inferior.

\section{Prega suprailíaca}

O indivíduo deverá estar em posição ortostática, visualizado pelo medidor lateralmente. A prega deverá ser formada com o polegar 
posicionado na linha média axial, imediatamente acima da crista ilíaca e com o dedo indicador diagonalmente seguindo a linha da pelve. $\mathrm{O}$ aparelho deve ser posicionado a, aproximadamente, $1 \mathrm{~cm}$ abaixo do desprendimento da prega.

\section{Diâmetro abdominal sagital}

É aferido com o indivíduo deitado em posição supina, com a face voltada para cima. No lado onde será aferida a medida, a mão é posicionada sobre o peito e o cotovelo alinhado ao corpo, sendo que o outro braço deve estar estendido ao longo do tronco. Deve-se localizar a crista ilíaca, traçar um ponto e transferi-lo com auxílio de uma fita inelástica para o centro do abdome (pode ou não coincidir com a cicatriz umbilical). A haste fixa do calibrador abdominal é posicionada sob as costas do paciente, e a móvel em cima do ponto transferido, mantendo o aparelho na posição vertical. É importante ressaltar que, mesmo em pacientes que apresentem algum desvio postural (cifose, lordose), a haste fixa do calibrador deverá ser posicionada sob as costas. A medida deve ser aferida no milímetro mais próximo, no momento da expiração.

\section{Considerações finais}

Considerando a importância das medidas na construção dos indicadores antropométricos, sendo de grande relevância na definição do diagnostico nutricional, estas devem ser realizadas seguindo, com bastante rigor, as técnicas de medidas, de forma a obter a maior precisão possível. Cuidados também não devem ser dispensados à qualidade dos instrumentos de medida que devem ser periodicamente aferidos por empresas e técnicos especializados. 
No quadro abaixo encontram-se sistematizados os erros mais comuns observados na aferição das medidas antropométricas.

\begin{tabular}{|c|c|c|}
\hline MEDIDAS & ERROS & SOLUÇÕES \\
\hline \multirow[t]{4}{*}{ TODAS } & Instrumento inadequado & $\begin{array}{l}\text { Adequação dos métodos aos } \\
\text { recursos }\end{array}$ \\
\hline & Leitura & $\begin{array}{l}\text { Treinamento exaustivo e } \\
\text { supervisão constante }\end{array}$ \\
\hline & Registro & $\begin{array}{l}\text { Registrar imediatamente os } \\
\text { resultados e ter os resultados } \\
\text { checados por outra pessoa }\end{array}$ \\
\hline & Inquietude da criança & $\begin{array}{l}\text { Solicitar ajuda dos pais e } \\
\text { utilizar procedimentos cultu- } \\
\text { ralmente apropriados }\end{array}$ \\
\hline \multirow[t]{4}{*}{ COMPRIMENTO } & Uso de sapatos & Remoção dos sapatos \\
\hline & Método incorreto para a idade & Apenas para crianças $<2$ anos \\
\hline & Posição do corpo e cabeça & Ajuda dos pais \\
\hline & $\begin{array}{l}\text { Posição do suporte na cabeça ou } \\
\text { nos pés (criança deitada) }\end{array}$ & $\begin{array}{l}\text { Ter um assistente, além de } \\
\text { um dos pais }\end{array}$ \\
\hline \multirow[t]{3}{*}{ ALTURA } & Método incorreto para a idade & $\begin{array}{l}\text { Apenas para crianças }>\text { ou }= \\
\text { a } 2 \text { anos }\end{array}$ \\
\hline & $\begin{array}{l}\text { Posição do corpo, joelhos dobra- } \\
\text { dos, pernas afastadas e pés não } \\
\text { posicionados firmemente sobre } \\
\text { o solo. Cabeça fora do plano }\end{array}$ & $\begin{array}{l}\text { Ter um assistente e estar aten- } \\
\text { to para corrigir a posição do } \\
\text { corpo. Ter bastante calma no } \\
\text { caso de crianças agitadas ou } \\
\text { que não querem colaborar }\end{array}$ \\
\hline & Posição do suporte na cabeça & $\begin{array}{l}\text { Suporte deve comprimir o } \\
\text { cabelo }\end{array}$ \\
\hline \multirow[t]{3}{*}{ PESO } & $\begin{array}{l}\text { Privacidade para retirada do } \\
\text { vestuário }\end{array}$ & $\begin{array}{l}\text { Local apropriado ou padro- } \\
\text { nizar vestimenta e subtrair } \\
\text { do peso }\end{array}$ \\
\hline & Balança não calibrada & $\begin{array}{l}\text { Usar se possível microele- } \\
\text { trônica ou calibrar a balança } \\
\text { antes de cada pesada }\end{array}$ \\
\hline & Inquietude do indivíduo & $\begin{array}{l}\text { Esperar até o indivíduo se } \\
\text { acalmar }\end{array}$ \\
\hline \multirow[t]{2}{*}{$\mathrm{CB}$} & $\begin{array}{l}\text { Posição do indivíduo/pressão } \\
\text { exercida pela fita }\end{array}$ & Treinamento, supervisão \\
\hline & $\begin{array}{l}\text { Marcação correta do ponto } \\
\text { médio }\end{array}$ & $\begin{array}{l}\text { Constante levar em conside- } \\
\text { ração questões culturais }\end{array}$ \\
\hline
\end{tabular}




\begin{tabular}{|c|c|c|}
\hline & Posição da fita /tipo de fita & $\begin{array}{l}\text { Usar sempre o mesmo braço/ } \\
\text { fita adequada }\end{array}$ \\
\hline MEDIDAS & ERROS & SOLUÇÕES \\
\hline \multirow[t]{2}{*}{$\begin{array}{l}\text { CIRC. DA } \\
\text { CABEÇA }\end{array}$} & $\begin{array}{l}\text { Marcadores da protuberância } \\
\text { occipital pobremente definidos }\end{array}$ & $\begin{array}{l}\text { Fita corretamente posicionada } \\
\text { exercitar bastante a técnica }\end{array}$ \\
\hline & $\begin{array}{l}\text { Tensão exercida na fita na hora } \\
\text { da leitura }\end{array}$ & $\begin{array}{l}\text { Remover qualquer enfeite } \\
\text { que altere o resultado }\end{array}$ \\
\hline \multirow[t]{4}{*}{ PCT } & Momento da leitura & Padronizar tempo \\
\hline & Posição do braço & Relaxamento do braço \\
\hline & $\begin{array}{l}\text { Posição do examinador em } \\
\text { relação ao instrumento }\end{array}$ & Treinamento sistemático \\
\hline & $\begin{array}{l}\text { Posição calibrador/profundidade } \\
\text { do pinçamento }\end{array}$ & Treinamento \\
\hline
\end{tabular}

Quadro 1 - Erros mais comuns observados na realização das medidas antropométricas

Fonte: Gibson (1990).

\section{Referências}

CHUMLEA, W. C.; ROCHE A. F.; MUKHERJEE A. Nutritional assessment of the elderly through anthropometry. Columbus, Ohio: Ross Laboratories, 1985.

GIBSON, R. S. Anthropometric assessment of growth. In: Gibson R. S. Principles ofnutritional assessment. New York: Oxford University Press, 1990. p. 163-186.

. Nutritionnal assessment: a Laboratory Manual. New York: University Press, 1993. 196 p.

LEE, R. D.; NIEMAN, D. C. Nutritional assessment. Londres: McGraw Hill, 1993.

LOHMAN, T. G.; ROCHE, A. F.; MARTORELL, R. Anthropometric standardization reference manual. Champaign: Human Kinetics, 1992.

ORGANIZAÇÃO MUNDIAL DA SAÚDE. Physical status: the use and interpretation of anthropometry. Genebra, 1995. Report of a WHO Expert Committee. (Technical Report Series, n. 854). 